\title{
Daily spatial mobility and transport behaviour in the Czech Republic: pilot study in the Písek and Bystrice and Pernštejnem regions
}

\author{
Stanislav Kraft \\ University of South Bohemia
}

This study focuses on one of the most important processes in our society: daily mobility. Its importance has grown over the last decades. From the geographical point of view, the growing level of mobility has a whole array of geographical causes and impacts.In the first phase, the study analyses the main features of daily mobility in the Czech Republic based on official statistics. In the second phase, it evaluates detailed daily mobility research in selected regions of the Czech Republic through case studies. The monitored regions were Písek and Bystrice nad Pernštejnem within their administrative regions. It brings new and original information about daily mobility, transport behaviour, modal split, average travel time, etc. and their differences evaluated by particular population groups (age, economic activity, gender, etc.) and by three main mobility measures. The study tries to fill a gap in the research of daily mobility and transport behaviour in the Czech Republic.

Key Words: Spatial mobility, Daily mobility, Transport behaviour, Pisek, Bystrice nad Pernštejnem, Czech Republic.

Article Info: Received: June 25, 2014; Revised: November 3, 2014; Accepted: November 14, 2014; Online: November 30, 2014.

\section{Introduction}

Mobility is an immanent and essential part of our lives. Workers, managers, students, pensioners, tourists and all other groups are nowadays characterized by a high amount of daily trips. People take these trips in order to satisfy their living needs and wishes. However, the areas where the essentials of life need to be satisfied have become increasingly widespread in the last few decades. Thus

\section{Correspondence address}

Address: University of South Bohemia in České Budejovice, Department of Geography Jeronýmova 10, 37115 České Budejovice, Czech Republic.

Phone: +420387 773062 | Email:kraft@pf.jcu.cz 
we are forced to travel longer distances and spend more time travelling than before. Growing mobility is typical for all parts of the world, even though there are rather large differences among them. Traditionally, inhabitants of regions with a high degree of economic and social development show the highest degree of mobility. On the other hand, even in developing countries the level of spatial mobility has begun to grow in importance (Adey 2009). This can be documented, for example, by global statistics from international tourism. In 2012, there were more than one billion international tourist arrivals, which was less than a half still in 1990 (UNWTO 2012). A similar trend can also be seen at the level of daily mobility (e.g. Hjorthol et al. 2010). Clearly our world is becoming more and more mobile. From the geographical point of view, the growing level of mobility has a whole array of important geographical causes and impacts (e.g. Cresswell 2006 or Gough 2008).

The main aim of the study is to analyze current daily mobility in the Czech Republic. The article focuses on 1) an analysis of main trends in daily mobility in the Czech Republic based on statistical data; and 2) a detailed study of daily mobility in selected regions of the Czech Republic through case studies. The first part gathers information from the results of the most recent census in the Czech Republic, which was carried out in 2011. Data about trends in commuting to work and school, which can be considered the main forms of spatial mobility, are analyzed. The second part of the study draws information from the empirical research on daily mobility in two model regions in the Czech Republic. The study aims to empirically prove or disprove generally accepted determinants of daily mobility through the study of traditional socio-demographic indicators of respondents (see below).

Although this area has already been heavily researched, there has been no attempt to conceptualize the transformation of mobility processes in the postsocialist context. The author was motivated to study this problem mainly due to the lack of adequate statistical data in the Czech Republic, which would allow at least the basic characteristics of daily spatial mobility to be studied. As a result, the problems of daily mobility have received scant attention so far, although they are an important factor in the socio-spatial organization of society. It can even be said that the problems of daily mobility have been so marginalized in the Czech Republic that they are interesting in and of themselves. The studied problems thus have a high social relevance and value. Thus the study tries to fill a gap in the research of this phenomenon in the Czech environment. The results of the study can therefore be an inspiration for geographers, transport planners, sociologists, cultural anthropologists, policymakers and others.

\section{Theoretical background}

Processes related to the mobility of people, goods, information and capital are at the centre of interest of various scientific disciplines, with geography, economics, sociology and cultural studies assuming leading positions. Spatial mobility and social mobility may be considered the main types of population mobility. While social mobility primarily focuses on the study of socioeconomic movements within social classes, spatial mobility is geared towards the analysis of territorial 
mobility processes under specific geographical conditions (Zelinsky 1971 and Kellerman 2012). The terms social mobility and spatial mobility, however, cannot be clearly separated from each other. Kaufmann (2002) states that these two types of population mobility are closely linked and interdependent.

The widely interpreted spatial mobility is then one of the key concepts of various disciplines in human geography, among which transport geography has a privileged position. Transport geography in particular studies various aspects of spatial mobility in a complex form (e.g. Hanson 2004). Based on the periodicity and reasons for movement, spatial mobility may be roughly divided into spatial mobility associated with a change of permanent residence (migration flows) and mobility without a change of permanent residence (circulation flows). Migration flows in particular have been monitored in both Czech and worldwide geography for a long time, as they were deemed more socially important and therefore at the core of human geographical research (Hampl 2005). In the context of current changes in spatial organization, however, also the changes in meaning of and new requirements for spatial mobility of people occur. As a result, particular forms of spatial mobility considerably change in favour of increasing sense, frequency as well as the spatial framework of the formerly less important circulation. These basically include the whole range of activities associated with the daily rhythms of our lives and, therefore, are highly relevant and important for our society.

The process of commuting to work, which is relatively well recorded in population censuses, has an especially unique position in the monitoring of periodical circulation flows of population. Its importance in human geographical research is undeniable, as it is considered the main form of human spatial mobility and, therefore, is crucial in the study of the spatial organization of society (e.g. Sýkora, Mulíček 2009), for example. Until now, however, much less attention has been paid to other forms of circulation flows (commuting to obtain services, commuting for recreational purposes, commuting for cultural purposes, etc.), which is logical in a way, as except in exceptional cases, no statistical records have been kept on these processes in the Czech Republic and in most other countries. This is all the more significant in that many studies have proven that work commutes are already a smaller share of all trips within daily mobility (e.g. Law 1999 and Scheiner 2006).

The specific development may be observed in the post-socialist states of Central Europe, that were characterized by the auto boom in the 1990's and other related processes (suburbanization, spatial de-concentration, etc.). In these countries, however, studies on the transformations of daily mobility patterns have emerged only rarely. Taylor (2003) notes that it is shocking how much information is available on migration flows being less important nowadays, while we know nearly nothing about the spatial mobility related to everyday activities. Spatial mobility processes, however, are monitored in a rather isolated way in the global and Czech geography, especially within settlement geography and the geography of services, etc. The transport-geographical viewpoint is less common, despite its apparent connection to the above processes in their complex form. The new mobility paradigm approaches and also the mobility turn in social sciences that monitor the mobility processes in their overall form using the interdisciplinary approaches of a number of scientific disciplines have recently 
begun to be employed (Sheller, Urry 2004, etc.), which represents a significant shift in the transport geography again towards the centre of spatial mobility research.

An important inspiration platform of daily spatial mobility research was based within the time-geography approaches. The elements of this platform are related to studies by the followers of the Lund School (Hägerstrand 1970, Ellegard 1999). The time-geography especially investigates into the forms of individuals' movement in space and time, since time and space are nonseparable and quantifiable values that are fitting for the study of socio-spatial organization of society (Drbohlav 1990 and Ira 2001). One of the most significant applications of time-geography is research on the time-space activities of individuals, used for transport planning (e.g. Beckmann et al. 1993). Among the later studies, the application of time-geography methods in the study of the daily movement of inhabitants in the suburban areas of Prague and in rural areas was addressed in studies by Novák, Sýkora (2007) and Novák, Temelová (2012). More recent studies dealing with practical time-geography applications point to the new era of research techniques in time-geography, which is directly related to the spreading of ICTs (Murakami, Wagner 1999).

Unfortunately, the approaches based on the time-geography methods are quite rare in transport geography. This is also mentioned in numerous studies that reveal important differences in the level, possibilities and needs for spatial mobility in urban, suburban and rural regions (Komornicki 2008, Nutley 1998, etc.). This leads to the next important characteristics that influence the intensity, periodicity, level and reasons for daily spatial mobility, namely the geographical environment conditions. Certain types of regions (rural, city, small-town, suburban) may also be considered, given their distinctive socio-economic conditions, specific as to the level of and demand for spatial mobility. In this context, the studies by Pucher and Renne (2005) or Nutley (2005) state that the need for higher mobility is a characteristic feature of non-urban areas, as the people living in them are forced to satisfy their common everyday needs, as a rule, in towns and cities that are further away. Similarly increased demand for mobility is newly exhibited by the suburban areas where the people, in some cases, have to rely on services and other socio-economic activities located in the central towns.

Urban areas are traditionally characterized by a relatively lower demand for spatial mobility, as especially in smaller towns some activities are localized within relatively short walking distance from residential districts. On the other hand, however, some authors state that urban regions in particular are often characterized by the highest rate of car numbers and that today's urban lifestyle is commonly linked to frequent movement and use of cars (Giuliano 1998). The study by Novák, Temelová (2012) comments that traditional socio-demographic categories used in studying everyday movements (age, education, sex, etc.) begin to be overlapped by new distinguishing levels (lifestyle, individual life attitude), which generally makes their interpretation more difficult. Also in this context, the variability and complexity of spatial behaviour patterns increase.

The geographical environment conditions also give rise to the social exclusion concept, which is inextricably linked with transport and daily mobility. Available modes of transport and the possibilities of daily mobility determined 
by them are traditionally regarded as a factor influencing the degree of social interactions (Law 1999). The term social exclusion refers to the situation in which some groups of people are excluded from common and necessary activities, although they do not want to be excluded and cannot change it (Cebollada 2009). The social exclusion of particular population groups in relation to their mobility may be interpreted in at least two ways. Traditionally, a variety of studies are concerned with the issue of living in rural regions that indicate a certain spatially determined social exclusion (Musil, Müller 2008). More recently, there has appeared social exclusion phenomena caused by the inability of people to drive a car (e.g. juveniles, persons without a driving licence, elderly people, etc.) and resulting in the respondents' reliance on public transport of varying quality (Preston, Rajé 2007).

\section{Methodology}

The empirical part of the research is based on an analysis of both secondary and primary data. In the first phase, the main aspects of daily mobility in the Czech Republic are assessed based on the results of the latest population census from 2011. The focus is on the main aspects of daily mobility as well as on transport behaviour by way of data about commuting to work and school. As mentioned above, these movements can be considered as the main forms of spatial mobility. Their analysis can therefore be applied to a conceptual framework of all the problems studied. Although the statistics on commuting to work and school are not always completely reliable (e.g. almost $30 \%$ of people did state the destination of their commute in the census), the results provide basic information about the spatial mobility of the population as a whole.

Therefore, primarily relativized characteristics are applied. The analysis focuses on recent developments in daily commuting between the last two censuses (2001 and 2011) and the modal split in daily commuting to work and schools in the Czech Republic. The second phase focuses on detailed research of daily mobility through two case studies. Detailed research of daily mobility was conducted by way of a sample survey of households in two model regions of the Czech Republic: Písek and Bystrice nad Pernštejnem (hereinafter referred to as 'Bystrice') - Figure 1. These regions have a mainly rural character and dominant administrative centres. The basic units were households in these regions and their members.

The aim was to gain information about the daily spatial mobility of individual household members in at least $0.8-1.0 \%$ of all multimember households in the given region. This value ensures a sufficiently representative sample of households in small-scale transport surveys (Richardson et al. 1995). In the Písek region, a total of 72 households were analyzed $(0.8 \%$ of all multimember households) and in the Bystrice region a total of 65 households $(1.1 \%$ of all multimember households) were analyzed. The second set of characteristics ensuring a sufficient representativeness of the sample was household separation by the size structure of municipalities in given region (tab.1). Also the age structure and economic activity of respondents complied with the proportionality of inhabitants of both monitored regions. The households were chosen 


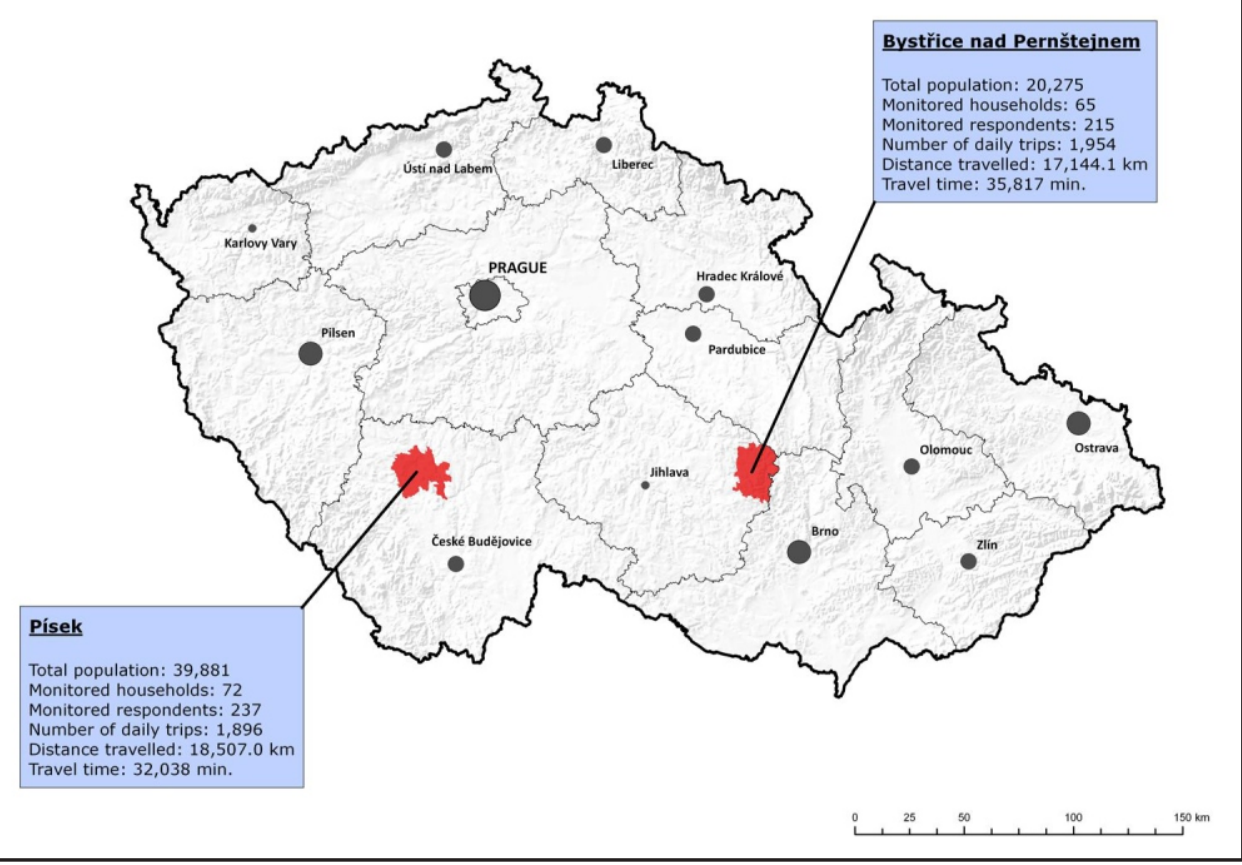

Figure 1. Daily mobility research areas (2012)

randomly, according to the population size of the municipalities, and according to their willingness to participate in the research.

The survey itself was carried out by means of a questionnaires distributed to households that determined the basic socio-economic characteristics of individual households (number of members, total monthly income, number of cars, age structure of the household, economic activity, etc.). The questionnaires were distributed by trained questioners. Each member of the surveyed household then received a travel diary, in which he or she noted information about all their daily trips in the course of three reference days in these categories: number of trips, travel time, distance, route of travel, purpose of trip, mode of transport used, periodicity of trips, etc. The monitored days were Monday, Wednesday and Saturday. This way, days of the week with different demands on daily mobility were optimally covered. The survey took place from October to November 2012. The resulting analyses included all persons above 12 years of age (people younger than 12 were not included in the survey due to the difficulty in filling in travel diaries and difficulty in providing representative answers).

A hundred and thirty-seven households were monitored over three monitoring days with 452 respondents. In the aggregate these respondents made more than 3,800 trips totalling more than 35,000 kilometres and 68,000 minutes of travel time (Table 1). 
Table 1. Number of monitored households according to population size

\begin{tabular}{|c|c|c|}
\hline Population in municipalities & $\begin{array}{c}\text { Number of monitored } \\
\text { households (Písek) }\end{array}$ & $\begin{array}{c}\text { Number of monitored } \\
\text { households (Byst ice) }\end{array}$ \\
\hline $0-99$ & 1 & 2 \\
\hline $100-199$ & 1 & 6 \\
\hline $200-499$ & 6 & 10 \\
\hline $500-999$ & 7 & 18 \\
\hline $1,000-2,999$ & 0 & 23 \\
\hline $3,000-9,999$ & 0 & 0 \\
\hline 10,000 and more & 57 & $\mathbf{6 5}$ \\
\hline TOTAL & $\mathbf{7 2}$ & 6 \\
\hline
\end{tabular}

Source: Own calculations

\section{Daily mobility and transport behaviour in the Czech Republic based on official data}

Official statistics concerning inhabitant mobility are relatively poor in the Czech Republic. The evaluation of daily mobility and transport behaviour can therefore be monitored only indirectly. From the available data sources (e.g. road transport census or traffic yearbook of the Czech Republic) it can be generally assumed that daily mobility has risen substantially in connection with the economic transformation of the Czech Republic after 1989 (similarly e.g. Komornicki 2008 for Poland). This is otherwise documented by data on traffic intensity on Czech roads for example. In the last five years, however, the rate of growth has slowed substantially. The main reasons are economic (economic crisis since 2008, rising fuel prices), demographic (changes in demographic behaviour), and technical (e.g. ageing of vehicles). Regardless, daily mobility remains on a level comparable with highly developed Western European states. The only area in which comprehensive information is officially provided about spatial mobility development is commuting to work and school.

An analysis of the main trends in commuting to work and school is important for framing mobility and transport behaviour in the longer term perspective. However, comparing the development of these two basic forms of spatial mobility is very difficult, due to the changing methodology of data collection and the decreasing relevance of this data source. In 2001, a total of 2,415,128 employed persons and 1,097,511 students commuted to work within a municipality. On the contrary, in 2011 the same indicators were 924,948 employed persons and 354,128 students. Clearly the data are not comparable, because in 2011 up to one third of people did not state the destination of their commute, and the method of proving commuting from the place of permanent residence (2001) changed to the place of habitual abode (2011). This substantially influenced the results, which makes their objective comparison impossible.

From the mentioned census at least the basic characteristics of transport behaviour and its changes can be compared. Under the terms of the census, each inhabitant had to fill in information not only about the about place of employment, but also the mode of transport used for commuting to work. A comparison of the importance of modes of transport used for daily commuting 


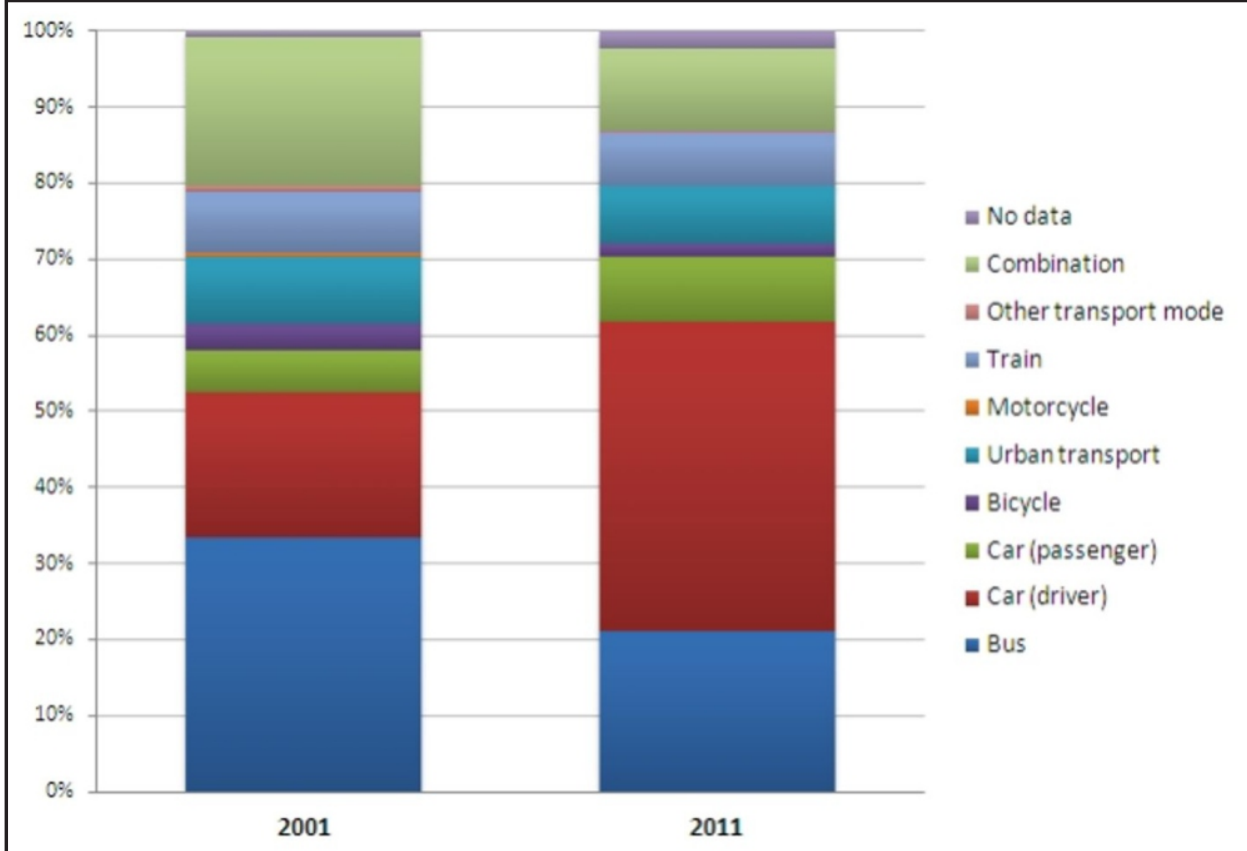

Figure 2. Modal split in commuting to work trips 2001 and 2011 Source: 2001 and 2011 Population and Housing Census

to work in the last two censuses shows the dominance of the car (Figure 2). In 2001 , it was used for daily commuting by more than 534,000 people $(24.6 \%$ of commuters), while in 2011 it was almost 670,000 (49.3\% of commuters). The growth of this dominance can be explained by common factors, such as easier car availability, increase in living standard of households, and so on. On the other hand, public transport registered a significant reduction. In 2001, bus transport accounted for almost a third of all commuters (over 773,000 people), while in 2011 it was only $21.0 \%$. Train transport registered a less significant reduction, with share of commuting travels ranging around $7 \%$. A similarly important share recently belongs to urban transport $(9 \%$ of all commuters in $2001,7.5 \%$ in 2011), whose use is, however, markedly spatially selective. Its use grows along with the increasing population size of the destination of the commute. On the contrary, bicycle commuting, motorcycle and other modes of transport register a relatively marginal share.

\section{Basic characteristics of daily mobility in the Písek and Bystrice regions}

The results of the detailed survey from the two model regions of the Czech Republic (Písek and Bystrice) clearly document the main aspects of daily spatial mobility (Table 2). On account of the different geographic conditions of the monitored regions (differences in settlement structure as well as economic, social and cultural differences) there are some differences between both regions in terms of daily spatial mobility. While the population of the Písek region, in the course of all monitored days, made an average of 2.7 trips per day, in the 
Bystrice region the average number of daily trips exceeded the value of 3 . We can also point out the differences in total distances and time spent travelling, which can be primarily ascribed to the rather more dispersed settlement structure of the Bystrice region, which determines a higher number of trips at longer distances. It nevertheless holds true that in both regions, the total daily mobility is approximately 45 - 55 minutes a day (almost $72 \%$ of all respondents). These values are stated in many local and international studies (Layos 2005), where values between 45 and 60 minutes are considered a kind of anthropologic constant, which a person is able to spend travelling daily. This constant is historically equal and is also markedly influenced by the availability of transport technologies (from walking at the start of the Industrial era to the modern era of the auto). More differences can be found nonetheless on account of relatively high representativeness of the examined sample it's interesting to watch identical signs of inhabitant mobility in both regions. In the sample, some common tendencies can be confirmed, which can be summed up in the following points:

1.There are obvious gender differences in daily mobility. In both monitored regions, on average the men perform a similar number of daily trips as women (2.65 vs. 2.69 in the Písek region, 2.97 vs. 3.08 in the Bystrice region), but men travel longer distances. Among other things, this suggests that men are more willing to travel longer distances on a daily basis. Women, on the other hand, usually stay closer to home (take care of the family, etc.), which is also related to the limited amount of time and distance that they are willing to spend on their mobility. This is also proved by other surveys, which show a lower overall mobility of women compared to men (Blumen 1994). Another interesting fact is that men show a higher rate of mobility especially during workdays, while on the weekends women travel more.

2.The overall daily mobility measured by number of trips, time and distances is markedly influenced by other socio-economic factors. The survey implies that one of the basic differential factors is the economic situation. The mobility of inhabitants among low-income households (less than CZK 20,000 per month) markedly differs. Low-income households show a limited amount of mobility, and it is bound particularly with trips to and from work or to school. For example, during the weekend these households have an average value of 1.71 travels, 13.24 kilometres and 26.46 minutes. In the case of the Bystrice region, the values are higher, but in the averages of the region as a whole there is again a direct proportion between the indicators of overall daily mobility and income. The exceptions among high-income households (more than CZK 50,000) are most likely influenced by the low number of households in this category. These values therefore cannot be considered fully relevant.

3. Daily mobility is also influenced by the respondents' age, although the differences are not immediately clear. Nevertheless, it holds true that a limited mobility extent is in average stands for younger age groups (particularly $12-17$ years), which are more markedly bound to home, and which have less access to cars. Similar characteristics can also be found among older people, who are again more bound to their homes and are often more dependent on pedestrian or public transport. The spatial frame of daily mobility is thus significantly smaller among teenagers and seniors, compared to other groups. Again, this can be documented by several studies (Timmermans et al. 2003), where especially 
among older age groups the phenomenon of social exclusion as a consequence of limited mobility options (e.g. accessibility of public transport and so on) is often mentioned. On the contrary, the younger and middle age category (usually economically active) are the most mobile, among which better availability of means and factors ensuring higher mobility (sufficient financial resources, car ownership, family care, business appointments) can be assumed.

4.Economic activity determines rather significant differences from the point of view of respondents' overall daily mobility. Generally it can be confirmed that higher mobility is typical for employed persons. These satisfy their daily mobility by commuting to work, shopping trips, visiting friends and family, etc. and are not as markedly limited in their mobility as the other groups. The highest mobility values are among self-employed persons, whose business activities are dependent on a high level of mobility. In international studies, this group of businesspeople and managers is usually labelled "hypermobile travellers" (Adams 1999). They are typified by frequent trips, often of very long distances. On the contrary, unemployed and retired people demonstrate some very limited values of daily mobility, which is again related with the economic situation discussed above and its manifestation in a limited meeting of needs and satisfaction of wishes.

5.The last category assessed includes car ownership in the monitored households. Although this category is usually considered one of the most important in daily mobility (e.g. Giuliano 1998), the results illustrate particularly noticeable differences between households without a car and those owning at least one. Especially in rural areas, households not owning a car show a much lower mobility level than households with a car. Again, in this context the social exclusion of the population can be appointed to as a consequence of their insufficient transport opportunities based on car ownership.

\section{Modal split in daily mobility in the Písek and Bystrice regions}

The second substantial feature of spatial mobility is the analysis of modal split. Intermodal differences in the use of modes of transport are basic characteristics of transport behaviour. The results are often used in transport planning. In the Czech literature this topic is given scant attention, which again relates to insufficient data concerning spatial mobility in the Czech Republic.

A whole array of factors influencing daily mobility is reflected in the results of the survey. From the whole overview of choice of modes of transport, a trivial conclusion can be confirmed, that overall daily mobility is substantially influenced by the availability of modes of transport. The most important factor can be considered the availability of a car, which represents the most important mode of transport in the Czech Republic. The values stated also document that usage of modes of transport varies during the day and week. With respect to the overall number of trips in the Písek region, the highest share falls on walking trips (52.8\% on workdays; $36.3 \%$ over the weekend). In the Bystrice region the adequate values are $43.7 \%$ or $37.6 \%$. These are particularly short trips, usually within a short distance of the respondents' place of residence. The overall distance allotted to walking trips ranges between five and 10 percent of 
Table 2. Basic characteristics of daily mobility in the monitored regions (average values per day)

\begin{tabular}{|c|c|c|c|c|c|c|}
\hline \multirow[b]{2}{*}{ SUM } & \multicolumn{3}{|c|}{ Písek $(n=237)$} & \multicolumn{3}{|c|}{ Byst ice $(n=215)$} \\
\hline & Trips & Distance & Time & Trips & Distance & Time \\
\hline & 2.67 & 26.03 & 45.06 & 3.03 & 26.58 & 55.53 \\
\hline \multicolumn{7}{|l|}{ Gender } \\
\hline Male & 2.65 & 35.53 & 48.17 & 2.97 & 33.56 & 60.12 \\
\hline Female & 2.69 & 16.38 & 41.87 & 3.08 & 20.16 & 51.97 \\
\hline \multicolumn{7}{|l|}{ Income } \\
\hline CZK $10-20,000$ & 1.92 & 10.30 & 28.38 & 2.41 & 21.29 & 40.59 \\
\hline CZK $20-30,000$ & 2.47 & 17.80 & 36.51 & 3.40 & 26.27 & 46.67 \\
\hline CZK $30-40,000$ & 2.94 & 35.80 & 54.06 & 2.95 & 29.46 & 48.15 \\
\hline CZK $40-50,000$ & 3.19 & 34.48 & 69.39 & 2.77 & 31.89 & 56.34 \\
\hline 50,000 and more & 2.35 & 18.45 & 25.61 & 2.80 & 34.98 & 54.77 \\
\hline \multicolumn{7}{|l|}{ Age } \\
\hline $12-17$ years & 2.28 & 18.24 & 39.99 & 3.06 & 13.70 & 48.21 \\
\hline $18-25$ years & 2.62 & 34.34 & 58.92 & 3.70 & 30.01 & 67.64 \\
\hline $26-35$ years & 2.67 & 15.60 & 34.57 & 3.24 & 34.17 & 58.36 \\
\hline $36-49$ years & 3.00 & 28.05 & 53.68 & 2.83 & 22.18 & 52.01 \\
\hline $50-64$ years & 2.22 & 10.86 & 24.06 & 2.57 & 19.37 & 44.53 \\
\hline $65+$ years & 1.66 & 3.70 & 15.09 & 2.30 & 5.44 & 25.75 \\
\hline \multicolumn{7}{|l|}{ Economic activity } \\
\hline Employed persons & 2.84 & 20.76 & 43.94 & 3.16 & 27.76 & 58.83 \\
\hline Self-employed persons & 3.02 & 54.69 & 84.20 & 2.97 & 42.73 & 73.23 \\
\hline Unemployed & 1.69 & 9.09 & 23.86 & 2.04 & 17.00 & 34.75 \\
\hline Students & 2.61 & 30.59 & 54.64 & 3.21 & 25.47 & 54.59 \\
\hline Parental leave & 1.91 & 14.76 & 29.91 & 2.42 & 17.69 & 44.28 \\
\hline Pensioners & 1.68 & 4.44 & 15.25 & 1.89 & 15.19 & 33.61 \\
\hline \multicolumn{7}{|l|}{ Car ownership } \\
\hline no cars & 2.07 & 5.95 & 25.87 & 2.75 & 12.50 & 41.18 \\
\hline 1 car & 2.77 & 21.17 & 43.69 & 3.50 & 25.98 & 52.58 \\
\hline 2 cars & 2.71 & 26.88 & 52.86 & 2.88 & 27.24 & 56.99 \\
\hline 3 cars & 2.58 & 45.92 & 59.99 & 2.97 & 36.03 & 56.67 \\
\hline 4 and more cars & - & - & - & 3.33 & 19.50 & 40.00 \\
\hline
\end{tabular}

Source: Daily mobility research 2012 , own calculations

distances carried out by this mode of transport. The dominant role is mostly played by trips carried out by car. Their share with respect to the number of trips ranges from 35 to $55 \%$. On the contrary, in terms of distance and travel time, car trips are the most important category, and usually accounts for half the share in each category. The cars are used more on the weekend days than on 
workdays. This fact is influenced by many factors. Among the most important are limited public transport services on weekends especially in rural areas, increased leisure time activities on weekends, commuting to weekly shopping, usually to bigger cities and by car (Vilhelmson 1999).

On the other hand, public transport accounts for a relatively marginal position with respect to utilization of modes of transport. The low share of urban mass transport (in all assessed categories in both regions the values range from one to four percent) can be explained by the fact that even though in both regions urban transport exists in the cities, due to its limited extent it cannot be considered crucial in such small towns. Train transport also accounts for only a small share of trips, since none of the monitored regions is located on an important railway line, which would influence the connection offer or quality. Among people without a car, therefore, most obligatory trips are carried out by bus, which can be documented particularly on working days, where bus transport comprises the second-most-important motorized mode of transport in both regions.

\section{Purposes of daily mobility in the Písek and Bystrice regions}

Daily mobility is primarily motivated by people's efforts to obtain the essentials of life. On that account, the purposes of individual trips were followed in the survey. From the geographic point of view these are noticeably differentiated, due to the uneven spatial allocation of socio-economic activities. Therefore it can be assumed that the purposes of particular trips will significantly reflect the spatial placement and frequency of daily activities. Subsequent analyses are therefore aimed at differentiating the purpose of individual trips according to

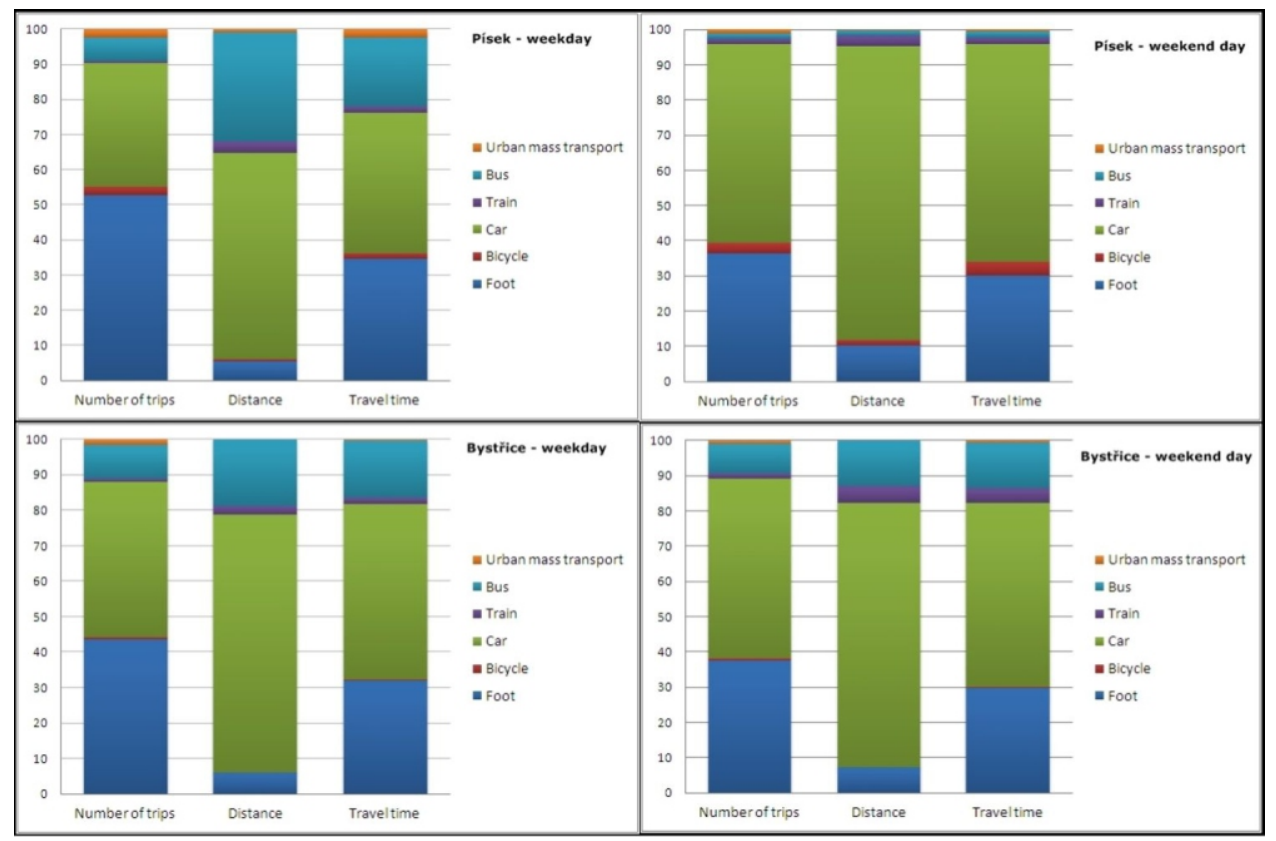

Figure 3. Modal split in monitored regions by number of trips, distance and travel time Source: Daily mobility research 2012, own calculations 


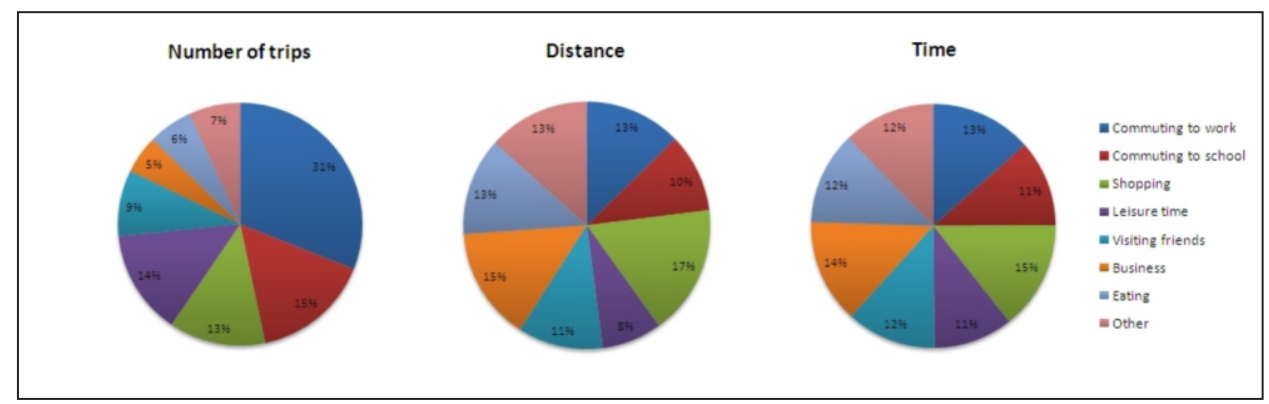

Figure 4. The purpose of daily trips by number, distance and travel time Source: Daily mobility research 2012 , own calculations

the frequency, distance and travel time needed for reaching these purposes. In terms of the frequency of trips from both regions, the highest share $(46.2 \%)$ consists of regular trips connected with commuting to work and school. In Western European countries these values range around $30-35 \%$ (e.g. Layos 2005). This confirms that commuting to work and school is the most important form of daily mobility. However, a comparison with other mobility purposes according to distance and travel time clearly shows that commuting creates a category comparable with the others. Shopping accounts for a permanently high share in number of trips, distance travelled and amount of time spent (13\% of trip count; $17 \%$ of distance travelled; $15 \%$ of time spent). It undoubtedly relates to tertiary activities being concentrated in urban areas and appearing only sporadically in rural areas. Trips related to leisure time and visiting friends are another important category, which accounts for an appreciable part of the trips within daily mobility.

The research of daily spatial mobility also monitored the differences in the modes of transport used according to the purpose of particular trips. These immediately reflect another substantial feature of transport behaviour. The primary factor influencing the intermodal differences according to the purposes are their different spatial demands following from the carried out distances. One trip takes about 20 minutes on average, which is a value comparable with the travel average following from the results of NHTS in the USA (NHTS 2009). Nevertheless, the trips according to purpose vary noticeably in the average distances that an individual is forced to travel in order to reach them. In both monitored regions walking is dominant for shorter trips (eating, leisure time), which are mostly carried out in the vicinity of the place of residence, workplace or school. A high share of walking trips is also typical for commuting to school. These are again trips with an average distance among both regions ranging usually from several hundred metres up to approximately two kilometres. The second most-utilized mode of transport is the car. It accounts for a dominant share of shopping trips, business trips, visits to friends and work commutes.

These trips are longer, but with similar characteristics of travel time (around 20 minutes per trip). Especially with business and shopping trips car transport makes up about three quarters of all trips. Public transport (in both regions mainly buses) has a relatively important position in commuting to work/school. It clearly demonstrates that public transport is competitive, particularly in the case of regular obligatory trips. On the contrary, in the case of irregular trips 


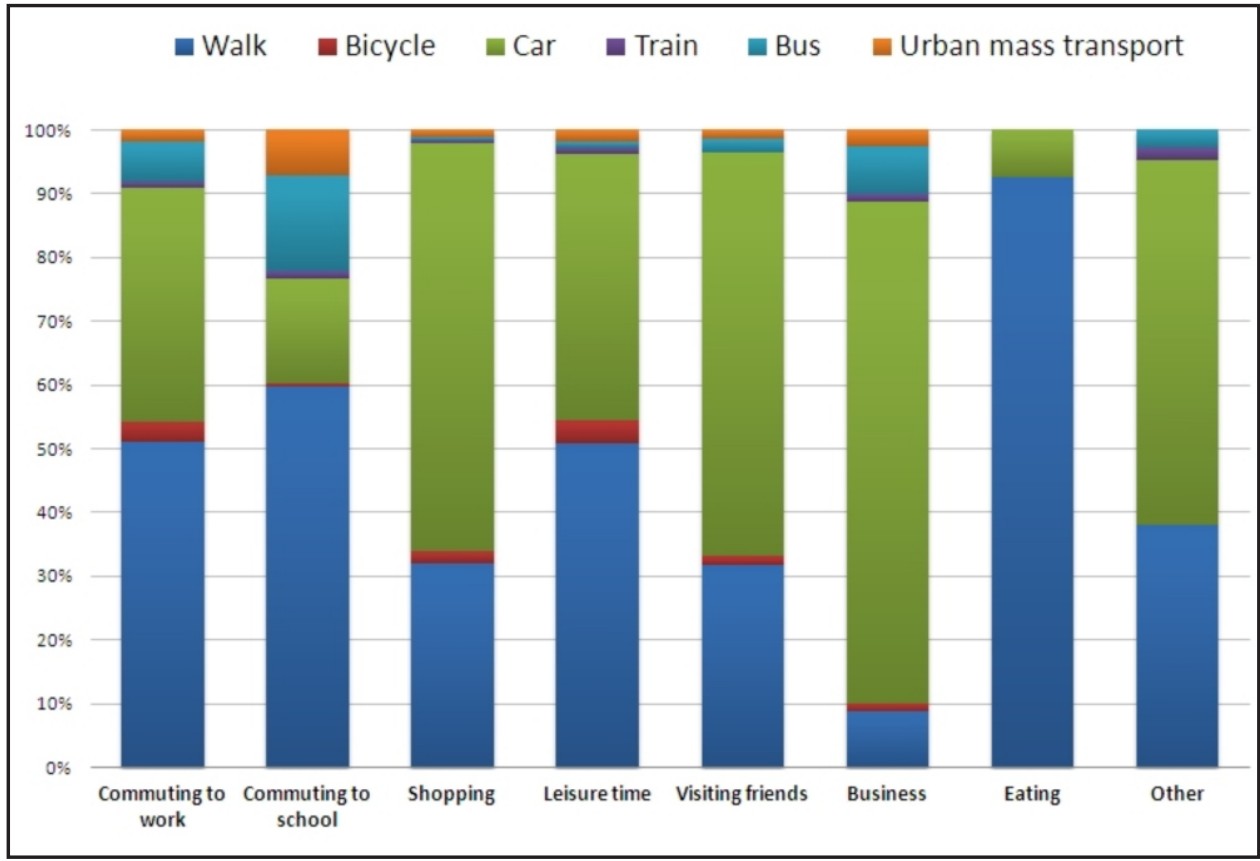

Figure 5. The purpose of daily trips by mode of transport

Source: Daily mobility research 2012, own calculations

(leisure time, visiting friends and shopping) its share in overall trips is marginal. In the case of bicycle transport, leisure time and commuting are the most common purposes, but account for at most a $5 \%$ share of all trips.

\section{Conclusions and recommendations for further research}

The main aim of the study was to provide an analysis of recent daily mobility patterns and transport behaviour in the Czech Republic. The study focused on comparing official statistics dealing with daily mobility and detailed data based on case studies in two model regions. From the resulting analyses, it was unambiguously clear that the issue of daily mobility is extremely complex. The official statistics on the study of transport as a whole are relatively poor and do little to reflect daily mobility. For this reason, the results of a pilot study on daily mobility in present-day Czech Republic were introduced in this study.

The results of the detailed survey confirmed the facts that were anticipated, namely that the mobility of inhabitants is one of the most important human activities. At the same time, it has been clearly proven that there are distinct social differences in the level of daily spatial mobility in the Czech Republic. The most important characteristics determining the overall level of daily spatial mobility measured by the number of daily travels, distance and time spent are total household income, economic activity and the age of individual respondents. Even though at present new factors influencing the intensity and spatial extent of daily mobility are emerging (e.g. Novák, Temelová 2012), basic sociodemographic indicators remain an important differential ground in the study of 
daily activities. From this point of view, the results of the study can be understood as primary information about the recent status of the daily mobility of the population in the Czech Republic. The study also shed light on some important differences of transport behaviour, because individual trips are often carried out through various modes of transport. The issue of transport behaviour in the conditions of the Czech Republic is still very little explored. The results of this study can therefore inspire further research into this phenomenon.

The results of the study are also crucial for transport geography itself. As mentioned above, the problems of daily mobility have been studied only sporadically in the Czech transport geography. In this way, the study can be an inspirational platform for other research with a similar focus in the post-socialist states of Central and Eastern Europe (similarly Popov 2012). The key question remains to what extent daily mobility in these states differs from that in other less and more developed regions. The post-socialist states of Central Europe can be truly perceived as a unique laboratory in the study of changes in daily mobility supported by other related processes (dynamic growth of car numbers, changes in settlement systems, growth of social stratification, demographic ageing of population, growth of living standards, etc.).

The facts introduced by this study should become the basis for broader research on daily mobility in these states. Emphasis should also be placed on matters of sustainable mobility, the influence of virtual mobility on the changes of physical mobility, and the consequences of increasing mobility on our society.

\section{Notes}

The study was supported by the Grant Agency of the Czech Republic (Spatial dynamics of transport relations in the settlement system of Czechia - reg. No. P4040121305). The author would like to thank Veronika Jindrová and Lukás Vícha for their help in the research.

\section{References}

Adams, J 1999, The social implications of hypermobility, OECD Project on Environmentally Sustainable Transport, UCL.

Adey, P 2009, Mobility, Routledge, Abingdon.

Beckmann, MJ, Golob, TF, Zahavi, Y 1983, Travel probability fields and urban spatial structure: 1. Theory, Environment and Planning A, vol. 15, no. 5, pp. $593-606$.

Blumen, O 1994, Gender differences in the journey to work, Urban Geography, vol. 15, pp. 223-245.

Cebollada, A 2009, Mobility and labour market exclusion in the Barcelona Metropolitan Region, Journal of Transport Geography, vol. 17, no. 3, pp 226-233.

Cresswell, T 2006, On the Move: Mobility in the Modern Western World, Taylor \& Francis.

Drbohlav, D 1990, Vnitromestská denní mobilita (na príklade pražských stredoškoláku), Zprávy Geografického ústavu ČSAV, vol. 27, pp. 47 - 63.

Ellegard, K 1999, A Time-geographical Approach to the Study of Everyday Life of Individuals - a Challenge of Complexity, GeoJournal, vol. 48, no. 3, pp. 167-175.

Giuliano, G 1998, Urban Travel Patterns, in R Knowles \& B Hoyle (eds) Modern Transport 
Geography, Chichester, Wiley, pp. 115 - 134.

Gough, K 2008, Moving around: The Social and Spatial Mobility of Youth in Lusaka, Geografiska Annaler B, vol. 90, no. 3, pp. 243 - 255 .

Hägerstrand, T 1970, What about people in regional science?, Papers of the Regional Science Association, vol. 24, pp. 7-21.

Hampl, M 2005, Geografická organizace společnosti v České republice: Transformační procesy a jejich obecný kontext, Praha, Univerzita Karlova v Praze.

Hanson, S 2004, The Context of Urban Travel - Concepts and Recent Trends, in S Hanson \& G Giuliano (eds) The Geography of Urban Transportation, pp. 3 - 29, The Guilford Press, New York.

Hjorthol, R, Levin, L \& Siren, A 2010, Mobility in different generations of older persons: The development of daily travel in different cohorts in Denmark, Norway and Sweden, Journal of Transport Geography, vol. 18, no. 5, pp. $624-633$.

Ira, V 2001, Geografia času: prístup, základné koncepty a aplikácie, Geografický časopis, vol. 53, no. 3, pp. 231-246.

Kaufmann, V 2002, Re-thinking mobility. Contemporary Sociology, Ashgate Publishing Company.

Kellerman, A 2012, Daily Spatial Mobilities: Physical and Virtual, Ashgate Publishing Company.

Komornicki, T 2008, Changes of car ownership and daily mobility in selected Polish cities, Geografický časopis, vol. 60, no. 4, pp. 339 - 362.

Law, R 1999, Beyond „women and transport“: towards new geographies of gender and daily mobility, Progress in Human Geography, vol. 23, pp. 567 - 588.

Layos, LA 2005, Short distance passenger mobility in Europe, Eurostat, Statistic in Focus Transport.

Murakami, E \& Wagner, D 1999, Can using global positioning system (GPS) improve trip Reporting?, Transportation Research C, vol. 7, pp. 149-165.

Musil, J \& Müller, J 2008, Vnitrní periferie v České republice jako mechanismus sociální exkluze, Sociologický časopis, vol. 44, no. 2, pp. $321-348$.

NHTS 2009, National Households Travel Survey.

Novák, J \& Sýkora, L 2007, A City in Motion: Time-Space Activity and Mobility Patterns of Suburban Inhabitants and Structuration of Spatial Organization in Prague Metropolitan Area, Geografiska Annaler B, vol. 89, no. 2, pp. 147-168.

Novák, J \& Temelová, J 2012, Každodenní život a prostorová mobilita mladých Pražan : pilotní studie využití lokalizačních dat mobilních telefonu, Sociologický časopis, vol. 48, no. 5, pp. 911-938.

Nutley, S 1998, Rural areas: The Accessibility Problem, in R Knowles \& B Hoyle (eds) Modern Transport Geography, Chichester, Wiley, pp. 185 - 215.

Nutley, S 2005, Monitoring rural travel behaviour: a longitudinal study in Northern Ireland 1979-2001, Journal of Transport Geography, vol. 13, no. 4, pp. 247 - 263.

Popov, V 2012, The culture of new mobility in Russia: Networks and flows formation, Mobilities, vol. 7, no. 1, pp. $151-169$.

Preston, J \& Rajé, F 2007, Accessibility, mobility and Transport-related social exclusion, Journal of Transport Geography, vol. 15, no. 4, pp. $151-160$.

Pucher, J \& Renne, J 2005, Rural Mobility and Mode Choice: Evidence from the 2001 National Household Travel Survey, Transportation, vol. 32, pp. 165-186.

Richardson, A, Ampt, E \& Meyburg, A 1995, Survey Methods for Transport Planning, 475 pp.

Scheiner, J 2006, Housing mobility and travel behavior: A process-oriented approach to spatial mobility. Evidence from a new research field in Germany, Journal of Transport 
Geography, vol. 14, no. 1, pp. $37-46$.

Sheller, M \& Urry, J 2006, The new mobilities paradigm, Environment and Planning A, vol. 38 , pp. $207-226$.

Sýkora, L \& Mulíček, O 2009, The micro-regional nature of functional urban areas (FUAs): lessons from the analysis of Czech urban and regional system, Urban Research and Practice, vol. 2, no. 3, pp. 287-307.

Taylor, Z 2003, Accessibility to facilities versus daily mobility of rural dwellers: The case of Poland, in G Higgs (ed) Rural Services and Social Exclusion, European Research in Regional Science, vol. 12, pp. 95-125.

Timmermans, H, Waerden, P, Aelves, M, Polak, J, Ellis, S, Harvey, A, Kurose, S \& Zandee, R 2003, Spatial context and the complexity of daily travel patterns: an international comparison, Journal of Transport Geography, vol. 11, no. 1, pp. 37 - 46.

UNWTO 2012, Annual Report.

Vilhelmson, B 1999, Daily mobility and the use of time for different activities. The Case of Sweden, GeoJournal, vol. 48, pp. 177 - 185.

Zelinsky, W 1971, The Hypothesis of the Mobility Transition, Geographical Review, vol. 61, pp. $219-249$. 